\title{
Population Dynamics of Released Potato Psyllids and their Bacteriliferous Status in Relation to Zebra Chip Incidence in Caged Field Plots
}

\author{
F. Workneh and L. Paetzold, Texas A\&M AgriLife Research, Bushland, TX 79012; A. Rashed, University of Idaho, Aberdeen Research and \\ Extension Center, Aberdeen, ID 83210; and C. M. Rush, Texas A\&M AgriLife Research, Bushland, TX 79012
}

\begin{abstract}
Workneh, F., Paetzold, L., Rashed, A., and Rush, C. M. 2016. Population dynamics of released potato psyllids and their bacteriliferous status in relation to zebra chip incidence in caged field plots. Plant Dis. 100:1762-1767.

Potato psyllids vector 'Candidatus Liberibacter solanacearum' (Lso), the putative causal agent of potato zebra chip (ZC). Currently, sticky traps are the primary psyllid monitoring tools used by growers for making management decisions. However, the reliability of sticky traps in predicting psyllid numbers in potato fields has always been questioned. In 2013 and 2014, experiments were conducted in covered field plots at the Texas A\&M AgriLife Research Station at Bushland to investigate the relationships among initial psyllid numbers, psyllids captured on sticky traps and their Lso status, and zebra chip incidence. Three densities of Lso-positive psyllids $(5,15$, or $30 /$ cage $)$ were released under 2 -week-old potato canopies with four replications in plot sizes of 7.6 to $9 \mathrm{~m}$ by 5 rows. Psyllids were released under the first plant in the center row and monitored weekly with a yellow sticky trap from the opposite end. Number of plants with zebra chip symptoms also was counted weekly beginning one month after infestation

with psyllids. The total number of psyllids captured on sticky traps and disease incidence levels generally corresponded to the levels of psyllid density treatments $(5<15<30)$, but the differences became more apparent toward the end of the experiments. Psyllid numbers in the different density treatments fluctuated more or less in synchrony over time, which appeared to reflect periodic emergence of new generations of psyllids. Initially, all captured psyllids tested positive for Lso. However, the proportions of psyllids testing positive declined dramatically after a few weeks, which suggested that the new generations of psyllids were devoid of Lso. Over all, less than $50 \%$ of captured psyllids tested positive for the pathogen. The decline in proportions of psyllids testing positive for Lso following successive generations has significant relevance to field situations and may partly explain why there are generally low percentages of Lso-positive psyllids under field conditions.
\end{abstract}

Zebra chip (ZC) is an important disease of potato first described in Mexico in mid 1990s and then in south Texas in 2000 (Secor and Rivera 2004; Secor et al. 2009). The disease is caused by the putative gram-negative alpha-proteobacterium 'Candidatus Liberibacter solanacearum' (Lso) syn. psyllaurous (Hansen et al. 2008; Liefting et al. 2008), which is vectored by the potato psyllid (Bactericera cockerelli) (Liefting et al. 2009; Munyaneza et al. 2007). The pathogen infects all plants in the family of Solanaceae including tomatoes, peppers, and other wild solanaceous species (Liefting et al. 2008, 2009). Affected potatoes show foliar symptoms of leaf curling, chlorosis, and proliferation of buds and aerial tubers at the nodes (Liefting et al. 2008; Munyaneza et al. 2007). The disease affects all market classes of potato and currently there is minimal genetic resistance in commercial cultivars. Tubers from affected plants exhibit browning of medullary rays, which turn dark when sliced and fried, rendering the product unmarketable (Munyaneza et al. 2007). Potato zebra chip is currently prevalent in most potato producing regions in the central and western United States, including the Pacific Northwest (Idaho, Oregon, and Washington), where it was observed for the first time in 2011 and caused substantial damage (Crosslin et al. 2012a, 2012b; Workneh et al. 2012).

Potato psyllids are native to North America and have been known to be associated with psyllid yellows disease for nearly a century (Richards and Blood 1933; Wallis 1946, 1955). However, the advent of ZC and the discovery that potato psyllids vector Lso has significantly changed potato culture and pest management. Use of insecticides

Corresponding author: F. Workneh; E-mail: f-workneh@tamu.edu

Accepted for publication 4 November 2015.

http://dx.doi.org/10.1094/PDIS-08-15-0904-SR

(C) 2016 The American Phytopathological Society for controlling psyllids has now become a routine practice each year, substantially increasing production costs. Although potato psyllids can quickly acquire Lso, not all psyllids in a population carry the bacterium (Munyaneza et al. 2008). A recent regional psyllid survey showed that the proportion of psyllids which tested positive for Lso was generally below 5\% (Goolsby et al. 2012). Under controlled conditions, nonbacteriliferous psyllids can acquire and transmit Lso in a matter of hours (Buchman et al. 2011; Rashed et al. 2012; Sengoda et al. 2013; Wang et al. 2015) and it is speculated that they also rapidly acquire the pathogen from infected hosts under field conditions. Thus, the proportion of Lso-positive psyllids at a given moment may depend on the hosts on which they have been feeding. Generally, samples from sticky traps in the Lower Rio Grande Valley (LRGV) contain a greater percentage of Lso-positive psyllids than those from elsewhere north (Goolsby et al. 2012). This may be attributed in part to the availability of perennial wild hosts such as wolfberry (Lycium spp.) in the area, which was shown to test positive for the bacterium (Goolsby et al. 2012).

Currently, sticky traps are the most widely used method for detection and quantification of psyllids in potato fields and counts from the traps are used for making management decisions. However, the sensitivity of sticky traps in quantifying psyllid numbers in potato fields has always been in question. For example, in regional field surveys (Goolsby et al. 2012; Workneh et al. 2013), the number of psyllids captured on sticky traps from growers' fields was quite high, but in most cases the vast majority of captured psyllids tested negative for Lso. However, the fields from which the psyllids were captured ended up with significant levels of ZC, suggesting that Lsopositive psyllids were in the fields at one time or another (Workneh et al. 2013). It has been hypothesized that once psyllids arrive in a field and settle at a favorable location, they are unlikely to move around frequently unless disturbed (Rashed et al. 2014). This is supported by the patchy distribution of ZC in the field and the fact that individual patches evolve in size over time (Henne et al. 2011). 
Sticky traps are designed to catch flying insects and, thus, are useful in detecting new influxes of psyllids into a field. However, it is questionable whether they are suitable for quantifying actual psyllid populations within a field. This is critical in designing management programs for potato psyllids and identifying action threshold levels for insecticide applications.

In the last few years, significant progress has been made in several areas of pathogen biology and disease epidemiology, but substantial knowledge gaps in our understanding of vector-pathogen-disease relationships still remain. The primary objectives of this project were to investigate i) relationships between actual psyllid numbers released into potato canopies and numbers caught on traps, ii) the Lso status of developing psyllid populations within cages over time, and iii) relationships between psyllid numbers and disease incidence.

\section{Materials and Methods}

The study was conducted at the Texas A\&M AgriLife Research Station at Bushland, Texas, under a center-pivot irrigation system. Potatoes (cv. FL1867) were planted on the first week of June 2013 on $76-\mathrm{cm}$ beds at $25-\mathrm{cm}$ spacing. Plots of $7.6 \mathrm{~m} \times 5$ rows then were marked off and covered with cages constructed of fiberglass rods, which formed the frame of the cages, covered with Econet mesh 4045 MAX (US Global Resources, Seattle, WA). The cages contained an average of 28 plants per row after emergence. Plants were infested with Lso-positive psyllids approximately 2 weeks after emergence. The infestation treatments contained 5, 15, or 30 psyllids in individual cages and each density treatment was replicated four times, for a total of 12 infested cages, plus a noninfested control cage. Psyllids for infestation were collected from an Lso-positive colony reared on infected potatoes in the greenhouse and has been known to test positive for Lso in repeated sampling (Wallis et al. 2015). Just prior to collecting psyllids for infestation, 10 psyllids from the greenhouse colony were randomly sampled and tested by qPCR, as previously described (Crosslin et al. 2011), and all testing positive for Lso. All psyllids in the greenhouse colony belonged to the central haplotype (Swisher et al. 2012) while the Lso haplotypes in individual psyllids were A+B (mostly) and B (Wen et al. 2009). The bacteriliferous psyllids collected from the greenhouse colony were placed in tubes and released at the base of the first plant of the center row in each cage. One week after psyllid infestation, one yellow sticky trap was placed on a 4-ft stake in each cage on the opposite end of the row on which the psyllids were released. Traps were collected and replaced weekly and psyllids on traps were counted under a stereoscope and tested for Lso by qPCR (Crosslin et al. 2011). Plants showing symptoms of ZC were recorded weekly, marked with stakes, and harvested 10 weeks after psyllid infestation. At harvest, tubers from symptomatic plants which had been marked were dug, sliced, and scored for the presence or absence of ZC symptoms. Once infection occurred, it takes about 3 to 4 weeks for foliar symptoms to develop. Therefore, to account for infected but nonsymptomatic plants, two tubers from every fifth plant in each row was dug and tested for Lso.

Analyses. Standard errors of the means for the number of psyllids captured on sticky traps and ZC incidence in the different psyllid density treatments were generated using the PROC MEANS procedure in SAS (SAS Institute Inc., Cary, NC). In addition, numbers of captured psyllds and the impact of the different psyllid densities on progress of ZC incidence over time were compared using paired $t$ test (paired by sampling dates) and the area under disease progress curve (AUDPC) using the equation $\sum_{i=1}^{n_{i}-1}\left(\frac{y_{i}+y_{i+1}}{2}\right)\left(t_{i+1}-t_{i}\right)$, where $n$ is the total number of assessment weeks, $y$ is $\%$ of infected plants at each week, and $t$ is week number (Madden et al. 2007).

The experiment was repeated in 2014 with similar treatments and replications. The length of the plot rows in each cage was extended to $9 \mathrm{~m}$, with an average of 33 plants per row after emergence. Potatoes were planted the third week of April and infested with psyllids as in the first experiment. The experiment was conducted for 15 weeks (psyllid infestation to harvest) and ZC symptom assessments in plants and tubers were conducted as described for the first experiment.

\section{Results}

The 2013 experiment was terminated earlier than anticipated because of malfunctioning of the center-pivot irrigation system, which
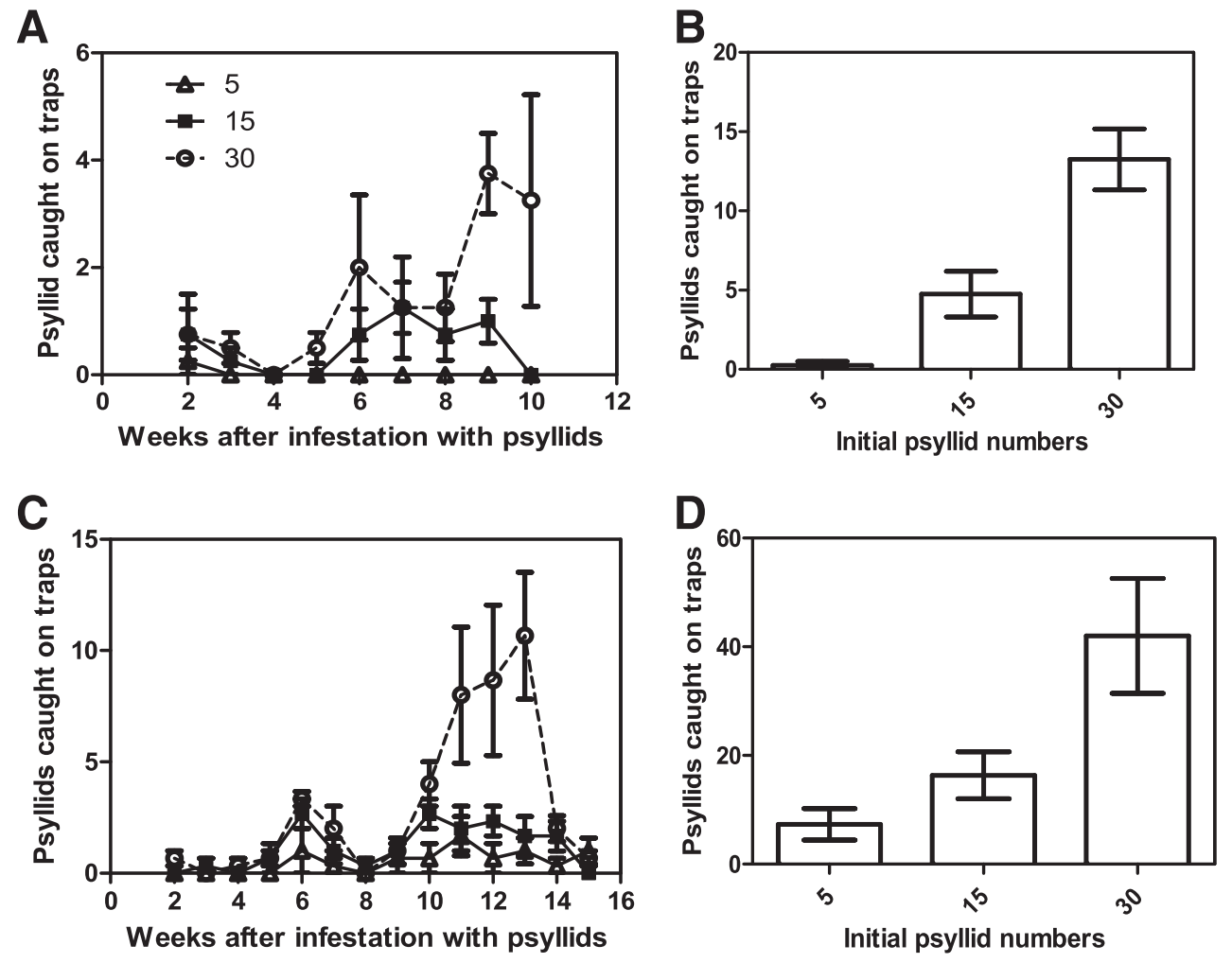

Fig. 1. Counts of psyllids on traps over time in the first $(\mathbf{A})$ and second experiment $(\mathbf{C})$, and the means of total psyllid numbers for both experiments (B and $\mathbf{D}$, respectively) for the initial three psyllid densities. 
sped up the onset of plant senescence. In the 2014 experiment, one of the cages was destroyed by high winds, and plants in another cage were defoliated by sphinx moths, which must have emerged from pupae surviving in the field soil. Thus, it was decided to run the experiment with three replications instead of four as initially intended.

Psyllid trapping. In both experiments only a few psyllids were caught on traps within 2 to 4 weeks after the initial infestation (Figs. 1A and C). However, psyllid numbers on traps began to increase after the fifth week, with the exception of the 5-psyllid density treatment in the first experiment in which only one psyllid was caught during the entire duration of the experiment. Overall in both years, psyllids were caught on traps in waves of alternating low and high numbers over time, and the patterns among treatments were more or less in synchrony, which appeared to reflect periodic emergence of new generations of psyllids at similar intervals. In all treatments (aside from the 5-psyllid density treatment in the first experiment), in both years, the number of psyllids detected rose 5 weeks after their release and began to decline on the seventh week only to rise again after the eighth week. The numbers of psyllids caught on traps did not show substantial differences among treatments until later in the study. After weeks 9 and 10, the 30-psyllid density treatment clearly separated itself from the other two with highest trap counts (Figs. 1A and C). Overall, the total psyllid numbers caught on sticky traps corresponded to the psyllid density levels (Figs. 1B and D). For the 2013 experiment, differences in the numbers of psyllids captured were significant only between the 5- and the 15- and the 5- and 30-psyllid treatments $\left(t_{8}=3.21, P=0.0125 ; t_{8}=3.31, P=0.0107\right.$, respectively) but not between the 15 - and 30-density treatment $\left(t_{8}=2.29, P=\right.$
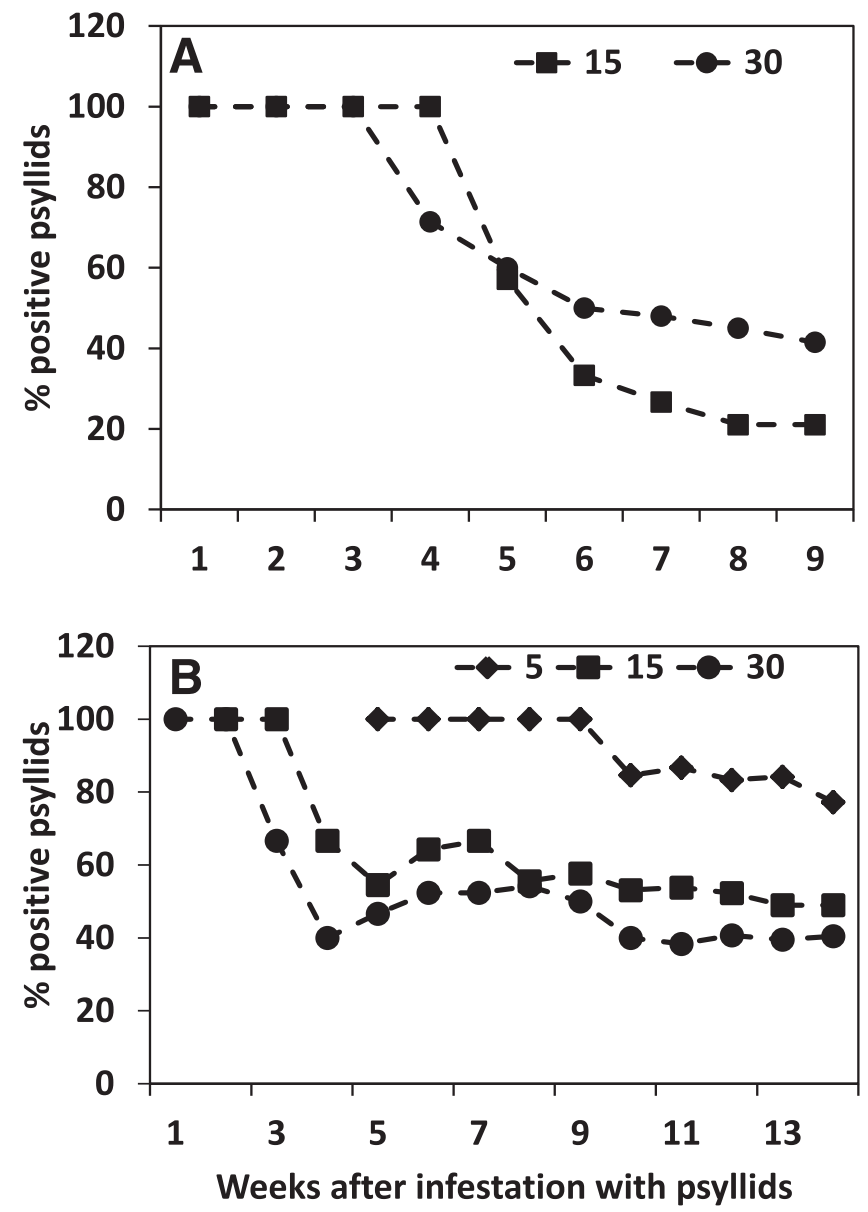

Fig. 2. Cumulative percentages of Lso-positive psyllids captured over time on traps in three psyllid densities $(5,15$, and 30$)$ for the first (A) and second experiments (B). One psyllid caught in the 5-psyllid-density treatment during the first experiment is not shown in $\mathrm{A}$.
0.0511). However, in the second experiment, significant differences were observed among all the treatments in numbers of psyllids captured $\left(2.27 \leq t_{13} \leq 3.18, P<0.05\right)$.

Psyllid testing. In both experiments, all psyllids that were collected from traps during the first 3 to 4 weeks tested positive for Lso. However, the percentage of psyllids testing positive for Lso declined dramatically thereafter (Figs. 2A and B). The declining period coincided with a rise in total numbers of psyllids captured (Figs. 1A and $\mathrm{C}$ ), which suggested emergence of new generations of psyllids devoid of Lso. In the first experiment, in addition to the single psyllid that tested positive in the 5-psyllid density treatment, 21.1 and $41.5 \%$ of psyllids collected during the entire experiment tested positive in the 15 and 30-psyllid density treatments, respectively (Fig. 3A). In the second experiment, $77.3,50$, and $40.5 \%$ of the psyllids tested positive in the 5, 15, and 30 density treatments, respectively (Fig. 3B). Overall, 37 and $47 \%$ tested positive in the first and second experiments, respectively.

Zebra chip assessments. In both experiments, disease symptoms began to appear 4 weeks after psyllid infestation in all psyllid-density treatments, at least on the first plant under which the psyllids were released. Trends in disease progression over time varied among the psyllid density treatments (Fig. 4A and C), with over time increase corresponding to initial psyllid numbers $(30>15>5)$ released in each cage. In the first experiment, differences in diseases progression over time were significant among psyllid treatments $\left(2.98 \leq t_{4} \leq 3.4\right.$, $P<0.05)$. In the second experiment, differences in $\mathrm{ZC}$ progression between individual pairs were highly significant $\left(6.31 \leq t_{10} \leq\right.$ 7.11, $P<0.0001)$. In both experiments, AUDPC also corresponded with the psyllid density treatment levels (Figs. 4B and D).

In the first experiment, in tubers dug from nonsymptomatic plants, the percentage of Lso-positive tubers corresponded with psylliddensity treatments ranging from 16 to $32.7 \%$ of tubers $(5<15<$ 30, Fig. 5A). However, the difference was significant only between the 5 and the 30-psyllid densities $\left(t_{3}=5.20, P=0.0139\right)$. In the second experiment, there were greater percentages of nonsymptomatic plants with tubers testing positive for Lso than in the first experiment, which ranged from 44.2 to $71.1 \%$. However, no significant difference was observed among the three treatments (Fig. 5B).

In all density treatments, the number of plants infected declined with distances from the psyllid release point until about the centers of the plots (Figs. 6A and B). However, disease levels increased thereafter, which was more evident in the second than in the first experiment. The number of infected plants at each measured distance away from the initial psyllid source corresponded to the psylliddensity treatments, the 30-psyllid density being the highest and the 5- the least.

\section{Discussion}

In the last decade, potato $\mathrm{ZC}$ has negatively impacted potato production in yield and quality. Since potato psyllids transmit the causal agent Lso, quantifying insect numbers in potato fields and relating their abundance to losses is imperative for implementing timely management actions. Currently, sticky traps are the primary tools used in psyllid surveys and the numbers of psyllids caught on traps serve as a guide for initiation of pesticide applications. The 2-year study provided useful insights into the relationship between initial psyllid numbers in potato canopies and those that were detected by sticky traps. Although overall the total number of psyllids caught on traps were significantly associated with initial psyllid numbers released in the cages, their inability to clearly distinguish among the psyillid densities early on confirmed the speculation that sticky traps are not sensitive at low psyllid numbers. Completion of a psyllid's lifecycle (egg to adult) takes approximately 3 weeks (Knowlton and Janes 1931) and fluctuations in psyllid numbers caught on traps appeared to reflect that time interval. This result suggests that sticky traps may be useful in detection of periodic spurts of insect numbers, resulting from emergence of new generations.

The most interesting finding in this investigation was the decline over time of $\%$ positive psyllids in all the psyllid density treatments. Although repeated samples from the psyllid colony prior to infestation 
showed that $100 \%$ of the psyllids were positive for Lso, overall, less than $50 \%$ of psyllids captured on sticky traps during the study tested positive for Lso. Those collected within 3 to 4 weeks of infestation tested positive, which suggested that they were members of the original release at the beginning of each experiment. The subsequent decline in the number of trapped Lso-positive psyllids appears to have begun with the emergence of new generations of psyllids, some of which did not harbor the bacterium. Secondary endosymbionts in insects are believed to be vertically (transovarially) transmitted to the offspring (Buckner 1965; Darby and Douglas 2003; Hosokawa et al. 2007). Lso
A

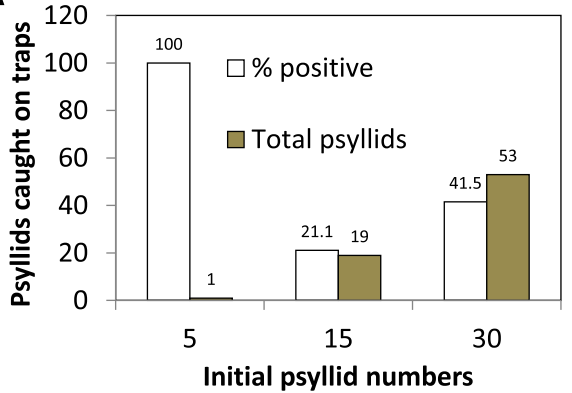

B

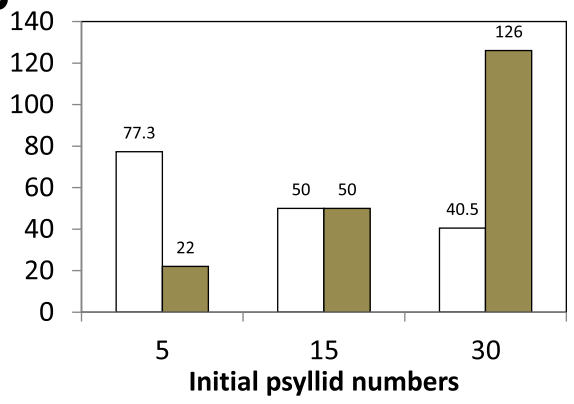

Fig. 3. Percentages of Lso-positive psyllids and total psyllid numbers in the first (A) and second (B) experiments in 5-, 15-, and 30-psyllid treatments.
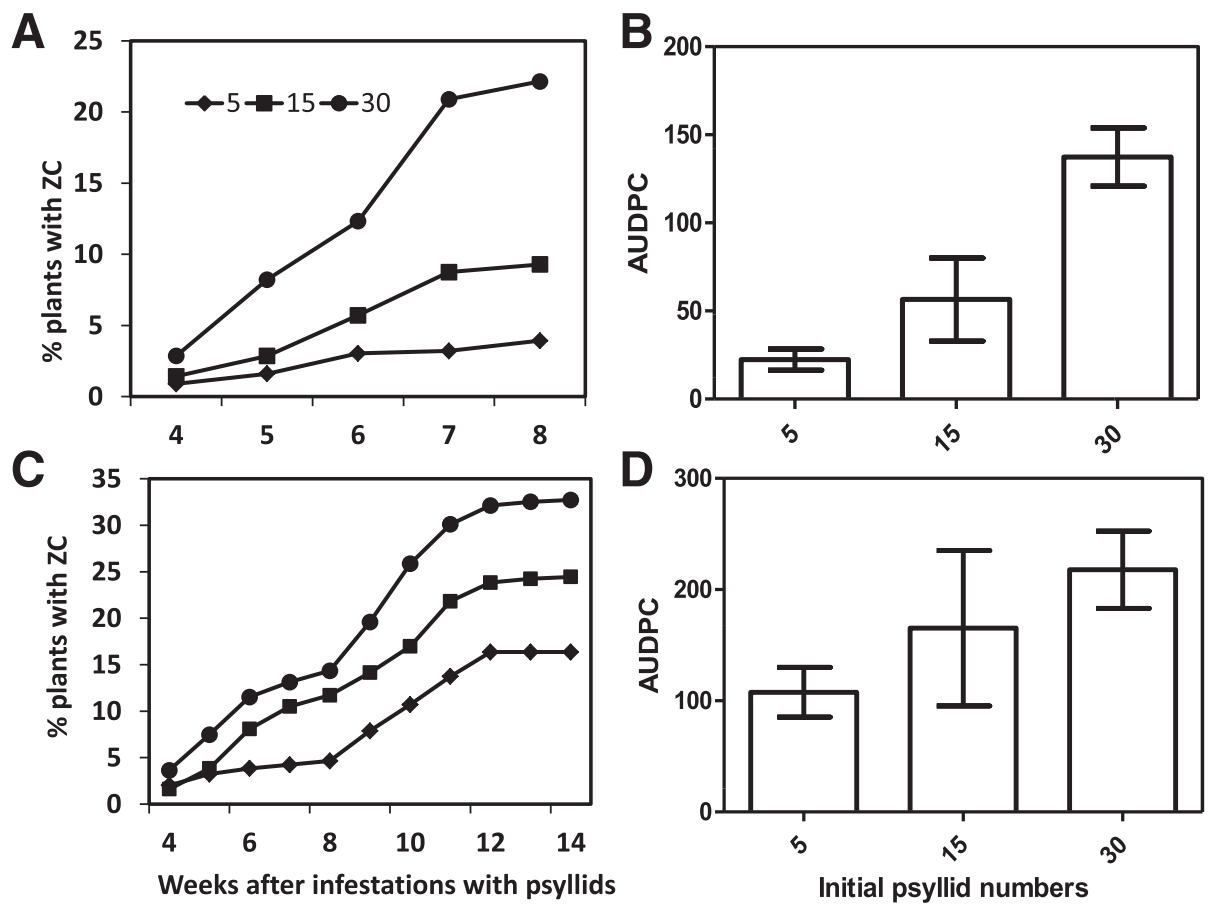

Fig. 4. Progression of zebra chip incidence over time in 5, 15, and 30-psyllid treatments in the first (A) and second experiments (C), and the corresponding area under disease progressive curves (AUDPC, B and D) for the respective psyllid densities.

A

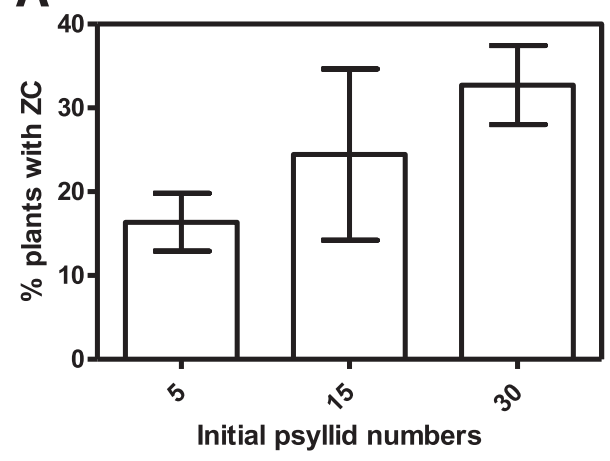

B

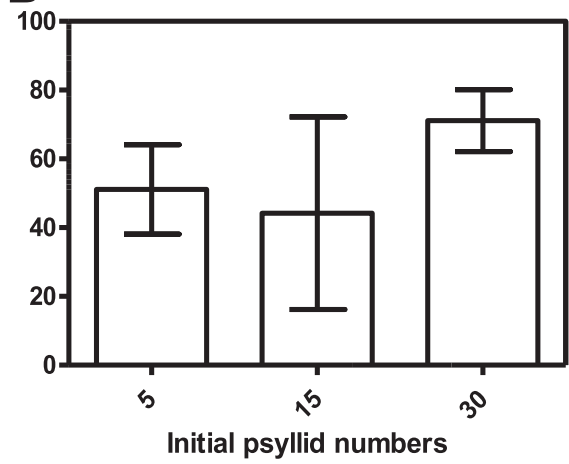

Fig. 5. Percentages of Lso-positive tubers obtained from nonsymptomatic plants for the first (A) and second (B) experiments. 
is a secondary symbiont in psyllids and psyllid eggs have previously tested positive for the bacterium confirming the transovarial transmission (Hansen et al. 2008). However, in many studied insects, there is a reduction in transmission of cell numbers of symbionts to the offspring, which is generally termed as "bottlenecks" in perpetuation of the symbionts through successive generations (Hosokawa et al. 2007; Mira and Moran 2002). Psyllids lay multiple eggs at one time (Knowlton and Janes 1931), and it is conceivable that some may harbor the bacterium while others may not. The titer level of Lso in the female psyllid may play a significant role in determining how much of the bacterium may be able to be vertically transmitted to the offspring (Hosokawa et al. 2007).

The second experiment had greater numbers of captured psyllids and also greater percentages of Lso positives than the first, most probably because the first experiment was shortened by 4 weeks compared with the second. Consequently, the percent positive psyllids in the second experiment was greater because the psyllids had a longer exposure to diseased plants and there were nearly $50 \%$ more diseased plants than in the first experiment, which provided a greater chance of acquiring Lso from infected plants. This result could have implications not only for in season pest management but also for late season infections, which are typically difficult to detect at harvest (Rush et al. 2015).

Tuber symptoms observed on nonsymptomatic plants were the results of late infection as it takes about 4 weeks for aerial symptoms to appear. In the second experiment, no significant difference was observed in tuber ZC incidence among the psyllid treatments. Although the overall disease incidence was under $35 \%$ in the weekly visual assessments, it is possible at the end (by harvest) that the lower psylliddensity treatments (5 and 15) may have begun catching up to the highest treatment (30) because of limited numbers of plants in the cages.

Under field conditions, the ratio of Lso-positive psyllids to the total population varies, but in most cases it has been less than 5\% (Goolsby et al. 2012). The low percentage may partly be attributed to the reduction in numbers of positive psyllids resulting from
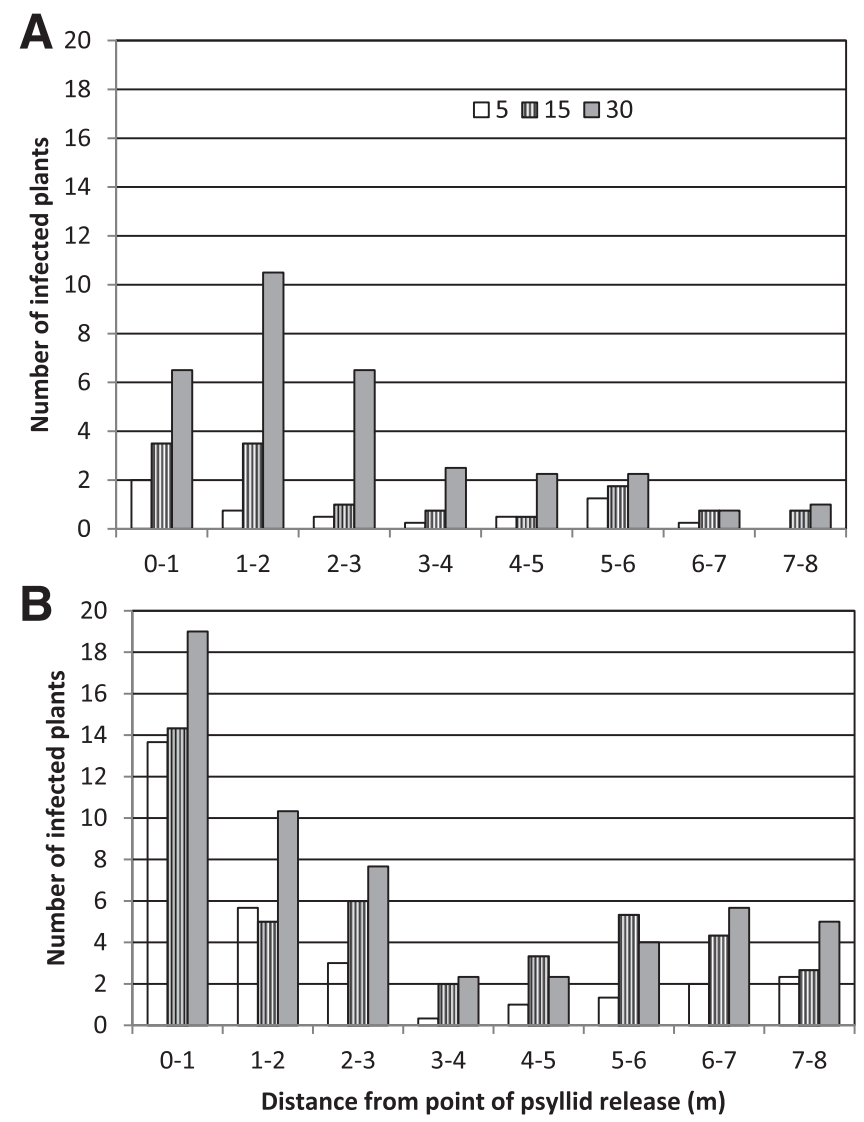

Fig. 6. Mean numbers of infected plants in relation to distance from the point of psyllid release for the three psyllid-density treatments in the first $(\mathbf{A})$ and second $(B)$ experiments. inefficient transovarial transmission of Lso (Buckner 1965; Darby and Douglas 2003; Hosokawa et al. 2007; Mira and Moran 2002). Additionally, since psyllids can acquire Lso from infected hosts, such as diseased potato plants and wild solanaceous species harboring the pathogen, it is possible that limitations in accessing infected hosts could play a significant role in further reducing populations of positive psyllids under field conditions.

In both experiments, the decline in number of infected plants in all psyllid densities from the initial point of psyllid release until the center of plots was not unexpected. However, what was not expected was the increase in disease levels from the center to the opposite end. It appears that the psyllids were avoiding the center of the plots but it could be that they tried to fly out from the opposite end but when trapped may have settled or reversed course and started feeding backward, creating a declining disease trend in the reverse direction. Greater disease incidence was also observed on the outer rows (edges) next to the cage walls (data not shown).

This study was the first of its kind in releasing known quantities of Lso-positive potato psyllids and attempting to relate subsequent pathogen/psyllid dynamics and disease incidence to psyllids captured on sticky traps over time. Overall, the sticky traps were able to distinguish among the different psyllid treatments, at least between the two extreme levels (5 and 30). However, most of the differences were observed later in the experimental stages following substantial rise in the number of psyllids, which supported the speculation that sticky traps are less sensitive at low psyllid numbers.

\section{Acknowledgments}

Funding for this study was provided by the TX ZC Research Initiative and the ZC SCRI, Grant \# 2009-51181-20176. We would also like to acknowledge technical support from J. Gray, J. Arthur, and A. Dupric.

\section{Literature Cited}

Buchman, J. L., Sengoda, V. G., and Munyaneza, J. E. 2011. Vector transmission efficiency of Liberibacter by Bactericera cockerelli (Hemiptera:Triozidae) in zebra chip potato disease: Effects of psyllid life stage and inoculation access period. J. Econ. Entomol. 104:1486-1495.

Buckner, P. 1965. Endosymbiosis of Animals with Plant Microorganisms. Interscience, New York.

Crosslin, J. M., Hamm, P. B., Eggers, J. E., Rondon, S. I., Sengoda, V. G., and Munyaneza, J. E. 2012a. First report of zebra chip disease and 'Candidatus Liberibacter solancearum' on potatoes in Oregon and Washington State. Plant Dis. 96:452.

Crosslin, J. M., Lin, H., and Munyaneza, J. E. 2011. Detection of 'Candidatus Liberibacter solanacearum' in the potato psyllid, Bactericera cockerelli (Sulc) by conventional and real-time PCR. Southwest. Entomologist 36:125-135.

Crosslin, J. M., Olsen, N., and Nolte, P. 2012b. First report of zebra chip disease and 'Candidatus Liberibacter solancearum' on potatoes in Idaho. Plant Dis. 96:453.

Darby, A. C., and Douglas, A. E. 2003. Elucidation of the transmission patterns of an insect-borne bacterium. Appl. Environ. Microbiol. 69:4403-4407.

Goolsby, J. A., Adamczyk, J. J., Crosslin, J. M., Toxclair, N. N., Anciso, J. R., Bester, G. G., Bradshaw, J. D., Bynum, E. D., Carpio, L. A., Henne, D. C., Joshi, A., Munyaneza, J. E., Porter, P, Sloderbeck, P. E., Supak, J. R., Rush, C. M., Willet, F. J., Zachmann, B. J., and Zens, B. A. 2012. Seasonal population dynamics of potato psyllid (Hemiptera:triozidae) and its associated pathogen 'Candidatus Liberibacter solancearum' in potatoes in the southern great plains of North America. J. Econ. Entomol. 105:1268-1276.

Hansen, A. K., Trumble, J. T., Stouthamer, R., and Paine, T. D. 2008. A new huanglongbing species, 'Candidatus Liberibacter psyllaurous', found to infect tomato and potato, is vectored by the psyllid Bactericera cockerelli (Sulc). Appl. Environ. Microbiol. 74:5862-5865.

Henne, D. C., Workneh, F., and Rush, C. M. 2011. Spatial patterns and spread of potato zebra chip disease in the Texas Panhandle. Plant Dis. 96:948-956.

Hosokawa, T., Kikuchi, Y., and Fukatsu, T. 2007. How many symbionts are provided by mothers, acquired by offspring, and needed for successful vertical transmission in obligate insect bacterial mutualism. Mol. Ecol. 16:5316-5325.

Knowlton, G. F., and Janes, M. J. 1931. Studies on the biology of Paratrioza cockerelli (Sulc). Ann. Entomol. Soc. Am. 24:283-292.

Liefting, L. W., Perez-Egusquia, Z. C., Clover, G. R. G., and Anderson, J. A. D. 2008. A new 'Candiddatus Liberibacter' species in Solanum tuberosum in New Zealand. Plant Dis. 92:1474.

Liefting, L. W., Weir, B. S., Pennycook, S. R., and Clover, R. G. 2009. 'Candidatus Liberibacter solanecearum' associated with plants in the family of Solanaceae. Int. J. Syst. Evol. Microbiol. 59:2274-2276.

Madden, L. V., Hughes, G., and van den Bosch, F. 2007. The Study of Plant Disease Epidemics. APS Press, St. Paul, MN. 
Mira, A., and Moran, N. A. 2002. Estimating population size and transmission bottlenecks in maternally transmitted endosymbiotic bacteria. Microb. Ecol. 44:137-143.

Munyaneza, J. E., Buckman, J. L., Upton, J. E., Goolsby, J. A., Crosslin, J. M., Gerhard, B., Miles, G. P., and Sengoda, V. G. 2008. Impact of different potato psyllid population on zebra chip disease intensity, severity, and potato yield. Subtrop. Plant Sci. 60:27-37.

Munyaneza, J. E., Crosslin, J. M., and Upton, J. E. 2007. Association of Bactericera cockerelli with "zebra chip", a new potato disease in southwestern United States. J. Econ. Entomol. 100:656-663.

Rashed, A., Nash, D., Paetzold, L., Workneh, F., and Rush, C. M. 2012. Transmission efficiency of 'Candidatus Liberibacter solanacearum' and potato zebra chip disease progress in relation to pathogen titer, vector numbers and feeding sites. Phytopathology 102:1079-1085.

Rashed, A., Workneh, F., Paetzold, L., Gray, J., and Rush, C. M. 2014. Zebra chip disease development in relation to plant age and time of 'Candidatus Liberibacter solanacearum' infection. Plant Dis. 98:24-31.

Richards, B. L., and Blood, H. L. 1933. Psyllid yellows of potato. J. Agric. Res. 46: 189-216.

Rush, C. M., Workneh, F., and Rashed, A. 2015. Significance and epidemiological aspects of late-season infections in the management of potato zebra chip. Phytopathology 105:929-936.

Secor, G. A. and Rivera, V. V. 2004. Emerging diseases of cultivated potato and their impact on Latin America. Rev. Latinoamericana Papa (Suppl.) 1:1-8.

Secor, G. A., Rivera, V. V., Abad, J. A., Lee, I.-M., Clover, G. R. G., Liefting, L. W., Li, X., and Boer, S. H. 2009. Association of 'Candidatus Liberibacter solancearum' with zebra chip disease of potato established by graft transmission, electron microscopy, and PCR. Plant Dis. 93:574-583.

Sengoda, V. G., Bachman, J. L., Henne, D. C., Pappau, H. R., and Munyaneza, J. M. 2013. 'Candidatus Liberibacter' titer over time in Bactericera cockerelli
(Hemiptera:Triozidae) after acquisition from infected potato and tomato plants. J. Econ. Entomol. 106:1964-1972.

Swisher, K. D., Munyaneza, J. E., and Crosslin, J. M. 2012. High resolution melting analysis of the cytochrome I Gene identifies three haplotypes of the potato psyllid in the United States. Environ. Entomol. 41:1019-1028.

Wallis, C. M., Rashed, A., Chen, J., Paetzold, L., Workneh, F., and Rush, C. M. 2015. Effects of potato psyllid-vectored 'Candidatus Liberibacter solanacearum' infection on potato leaf and stem physiology. Phytopathology 105:189-198.

Wallis, R. L. 1946. Seasonal occurrence of potato psyllid in the North Platte Valley. J. Econ. Entomol. 39:689-694.

Wallis, R. L. 1955. Ecological studies on the potato psyllid as a pest of potatoes. USDA Tech. Bull. 1107.

Wang, N., Yan, Q., Workneh, F., Rashed, A., and Rush, C. M. 2015. 'Candidatus Liberibacter' spp. and related diseases. Pages 287-305 in: Virulence Mechanisms of Plant Pathogenic Bacteria. N. Wang, J. Jones, G. Sundin, F. White, S. Hogenhout, C. Rober, L. De La Fuente, and J. Ham, eds. APS Press, St. Paul, MN.

Wen, A., Mallik, I., Alvarado, V. Y., Pasche, J. S., Wang, X., Li, W., Levy, L., Lin, H., Scholthof, H. B., Mirkov, T. E., Rush, C. M., and Gudmestad, N. C. 2009 Detection, distribution, and genetic variability of 'Candidatus Liberibacter' species associated with zebra chip complex disease 1 of potato in North America. Plant Dis. 93:1102-1115.

Workneh, F., Henne, D. C., Goolsby, J. A., Crosslin, J. M., Whipple, S. D., Bradshaw, J. D., Rashed, A., Paetzold, L., Harveson, R. M., and Rush, C. M. 2013. Characterization of management and environmental factors associated with regional variations in potato zebra chip occurrence. Phytopathology 103: 1235-1242.

Workneh, F., Mirik, M., Rashed, A. Hamm, P. B., Ansley, A., and Rush, C. M. 2012. Potato zebra chip in the Pacific Northwest: Impact and probable psyllid source assessments (Abstr.). Phytopathology 102:S4.137. 